\title{
Thermal Analysis of the Impact of RT Storage Time on the Strengthening of an Al-Mg-Si Alloy
}

\author{
A. Hayoune \\ Nuclear Research Centre of Birine, Ain Oussera, Algeria. \\ Email: athayoune@yahoo.fr \\ Received March $5^{\text {th }}, 2012$; revised April 10 $0^{\text {th }}, 2012$; accepted May $9^{\text {th }}, 2012$
}

\begin{abstract}
Despite the large number of papers dealing with the Al-Mg-Si system, the decomposition of the supersaturated solid solutions during the different aging treatments and therefore, the related hardening is still under debate., In the present work, by the use of simple techniques such as the Differential Scanning Calorimetry (DSC), Microhardness measurements and X-Ray Diffraction (XRD) analysis the precipitation behaviour and the impact of prior natural aging after homogenization on the subsequent microstructural and mechanical evolutions during artificial heat treatment at $160^{\circ} \mathrm{C}$, of nuclear aluminium alloy $\mathrm{Al}-1.32 \% \mathrm{Mg}-0.53 \% \mathrm{Si}$ (wt.\%) alloy, were identified. Through DSC, lattice parameter and microhardness measurements, the precipitation sequence were indirectly identified to be as follows: supersaturated solid solution (S.S.S.) $\rightarrow$ atomic clusters and GP zones $\rightarrow \beta^{\prime \prime} \rightarrow \beta^{\prime} \rightarrow \beta$. The evolution of the mechanical properties during natural aging has been explained to be due to GP zones and atomic clusters formation. Storage at RT was found to have an important effect on the mechanical properties of the studied alloy. Under the light of the DSC results, this effect was explained by a slower precipitation kinetics of the $\beta^{\prime \prime}$ phase; the atomic clusters and GP zones, which formed during storage at RT and the low concentration of the quenched-in vacancies in the stored samples have a delaying effect upon the nucleation of $\beta^{\prime \prime}$ phase. Consequently, the final microstructure developed in these samples is coarse; hence lower mechanical properties are obtained.
\end{abstract}

Keywords: Al-Mg-Si Alloy; Precipitation; DSC; Natural Aging; Microhardness

\section{Introduction}

Since the discovery of age hardening of Al-Mg-Si alloys some 90 years ago a significant amount of work on characterising and understanding the precipitation behaviour of these alloys has been carried out [1-15]. Factors such as low degree of activation during irradiation, high corrosion resistance in vapour-water media, high weldability, medium strength, high extrudability have supported the usage of these alloys as structural materials in the industry of nuclear research reactors [1].

These alloys undergo complex structural changes during heat treatment. The extent of these structural changes depends on the applied temperature, the time the material is exposed to temperature, and how fast it is cooled to room temperature. Despite the considerable literature devoted to this subject [2-15], these structural changes have not been fully understood. However, it was generally accepted that the precipitation behaviour follows the scheme: supersaturated solid solution (S.S.S.) $\rightarrow$ atomic clusters $\rightarrow$ GP zones $\rightarrow$ metastable $\beta^{\prime \prime} \rightarrow$ metastable $\beta^{\prime}$ $\rightarrow$ stable $\beta$ and that, their properties are highly dependent on the distribution of the alloying elements, $\mathrm{Mg}$ and $\mathrm{Si}$, in the matrix and in the developed precipitates.

It is well known that heat treating variables in addition to the final aging time and temperature can have a marked effect on the hardening response of heat-treatable aluminum alloys. Examples of such variables are: delay time between solution heat treating and aging (natural aging), heating rate to the aging temperature, and aging at an intermediate temperature prior to final aging (preaging). Generally, natural aging and preaging treatments are beneficial; they promote fine, uniform precipitate dispersions and high strength $[10,12,14]$. The situation appears to be more complicated in the Al-Mg-Si system due to the fact that the precipitation reactions in this alloys system are very sensitive the alloys compositions and the ally history.

The precipitation behaviour of these materials is basically investigated based on both the thermal stabilities and the structural aspects of stable/metastable phases. Differential Scanning Calorimetry (DSC) measurements and Transmission Electron Microscopy (TEM) observations are very helpful tools for this purpose. In the present work a study based on a combination of simple 
techniques such as Vickers microhardness tests, differential scanning calorimetry (DSC) and X-ray diffraction analysis is presented. It aims to investigate the precipitation behaviour and the impact of prior room temperature aging upon subsequent artificial aging at $160^{\circ} \mathrm{C}$ of an Al- $1.32 \% \mathrm{Mg}-0.53 \% \mathrm{Si}$ (wt.\%) alloy.

\section{Experimental Procedure}

The alloy investigated in this study is a base aluminium alloy of the chemical composition of $\mathrm{Al}-1.32 \% \mathrm{Mg}-0.53 \% \mathrm{Si}$ (wt.\%) alloy. The alloy contains also a small amount of iron (0.094 wt.\%) and smaller amounts of other elements ( $\mathrm{Zn}, \mathrm{Cu}$ and $\mathrm{Ni}$ ). The alloy was received as $2 \mathrm{~mm}$ thick sheets. Specimens for microhardness measurements, DSC and XRD analyses were cut from the sheets with a metallographic diamond cutting saw, and grounded to their final shape with emery papers. Final mass of each DSC sample was about $60 \mathrm{mg}$. All samples were solution treated at $540^{\circ} \mathrm{C}$ for $6 \mathrm{~h}$ and subsequently cooled by quenching in water at room temperature (WQ). Immediately after quenching, the samples were held at about $-15^{\circ} \mathrm{C}$ to prevent any microstructural evolution.

As quenched samples as well as annealed at room temperature and $160^{\circ} \mathrm{C}$ have been submitted to microhardness measurements and DSC analysis. Vickers microhardness measurements were carried out at room temperature immediately after each aging treatment, using a Controlab (VTD 12 Model) microhardness tester under a $2.94 \mathrm{~N}$ load applied for 10 seconds, and an average of at least seven readings were taken for each specimen.

For DSC analysis, tests were performed with a Setaram-SetsysEvolution-1600 DSC apparatus. Temperature and heat flow calibration has been carried out using pure In, $\mathrm{Sn}, \mathrm{Zn}$, and $\mathrm{Ag}_{2} \mathrm{SO}_{4}$ melting and phase transition points under nitrogen atmosphere. Tests were performed by heating from room temperature (RT) to $540^{\circ} \mathrm{C}$, and then by cooling to RT at $30^{\circ} \mathrm{C} \cdot \mathrm{min}^{-1}$ in all cases. To increase measurement sensitivity, a high-purity well annealed aluminium disc of mass approximately equal to that of the sample was used as a reference in each case. Both reference and specimen were enclosed in an alumina pan sealed with an alumina cover. The DSC traces presented in this work were obtained by subtracting the base line from the first run. The base line was obtained from a run with a high-purity well annealed aluminium disc of the same mass in both the sample and the reference pans.

The XRD patterns were collected on a Philips X'-Pert Pro diffractometer using $\mathrm{Cu} \mathrm{K} \mathrm{K}_{\alpha}$ radiation with X-ray generator power set at $1.8 \mathrm{~kW}(45 \mathrm{kV}$ and $40 \mathrm{~mA})$. In order to characterize the microstructure in term of lattice parameter variations, room temperatures scans were performed in the angular range of 15 - 120 with a step size of 0.02 . The lattice parameter measurements were done with the help of X'Pert HighScore Plus software.

\section{Results and Discussion}

\subsection{The Precipitation Sequence}

A total of seven enthalpic signals (numbered I-VII), four of which are exothermic, are identified in the DSC spectrum, obtained by heating at $15^{\circ} \mathrm{C} \cdot \mathrm{min}^{-1}$ of the as quenched sample (Figure 1). According to several previous works [4-6,8,9,12-14], these calorimetric events can be correlated to the precipitation process as follows:

- The first exothermic peak centring around $100^{\circ} \mathrm{C}$ (effect I) is caused by GP zones and/or clusters formation;

- The small endothermic signal with a minimum at approximately $220^{\circ} \mathrm{C}$ (effect II) is produced by the dissolution of the clusters and/or GP zones which have formed below $150^{\circ} \mathrm{C}$;

- The major exothermic peak which follows right after and lasts until $300^{\circ} \mathrm{C}$ (effect III) is clearly linked with the precipitation of the principal hardening phase $\beta^{\prime \prime}$. The neighbouring exothermic peak between approximately $300^{\circ} \mathrm{C}$ and $340^{\circ} \mathrm{C}$ (effect IV) is produced by the transformation of $\beta^{\prime \prime}$ to $\beta^{\prime}$. The large endothermic peak between approximately $340^{\circ} \mathrm{C}$ and $430^{\circ} \mathrm{C}$ (effect V) represents the dissolution reaction of the $\beta^{\prime}$ phase;

- The last two peaks are exothermic and endothermic (effects VI and VII) are associated with the precipitation and dissolution of the equilibrium $\beta-\mathrm{Mg}_{2} \mathrm{Si}$ phase, respectively. It is fair to claim, that some authors [9, 15] have not mentioned the presence of the endothermic peak $\mathrm{V}$ in between exothermic peaks for the formation of $\beta^{\prime \prime}$.

The type of the precipitate responsible of each calorimetric peak has been checked through lattice parameter

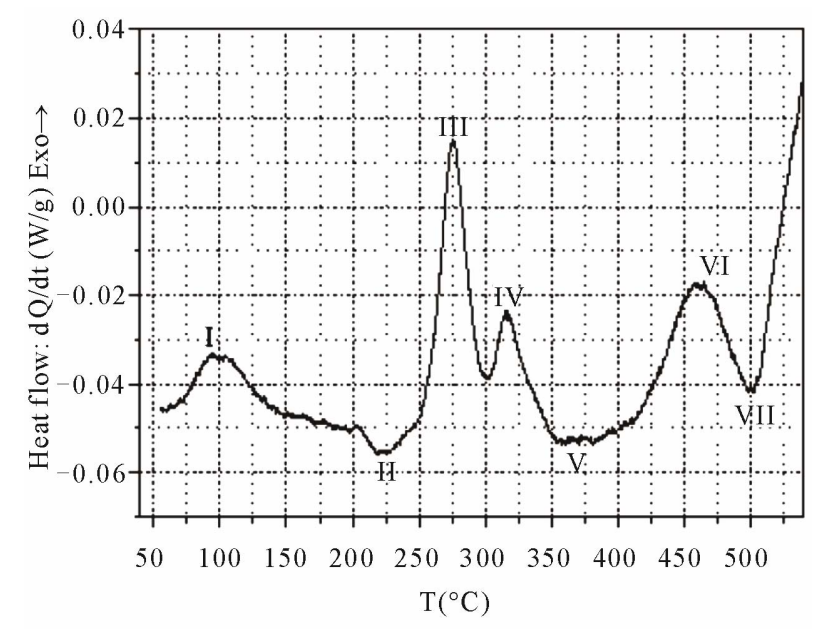

Figure 1. DSC spectrum obtained at a heating rate of $15^{\circ} \mathrm{C} \cdot \mathrm{min}^{-1}$ of the as quenched sample. 
and microhardness measurements. Due to the size differences between solute and aluminium atoms $\mathrm{Si}$ and $\mathrm{Mg}$ for which $\Delta \mathrm{r}_{\mathrm{Si}}=-3.8 \%$ and $\Delta \mathrm{r}_{\mathrm{Mg}}=+11.8 \%$ where $\left.\Delta \mathrm{r}_{\mathrm{Si}}=\left(\mathrm{r}_{\mathrm{Si}}-\mathrm{r}_{\mathrm{Al}}\right) / \mathrm{r}_{\mathrm{Al}}\right)$, the formation of solute rich precipitates $\left(\beta^{\prime \prime}, \beta^{\prime}\right.$ and $\left.\beta\right)$ should decrease the lattice parameter [16-18]. Lattice parameter and microhardness measurements obtained from samples heated for $20 \mathrm{~min}$ at temperatures corresponding to the different DSC peaks are presented in Figure 2. It can be seen that the calorimetric peaks III, IV and VI are corresponding to a decreasing of the lattice parameter values. However, the calorimetric effect $(\mathrm{V})$ is associated with an increasing of the lattice parameter values. Hence, the calorimetric effects (III), (IV) and (VI) are representative of precipitation reactions (i.e. $\beta^{\prime \prime}, \beta^{\prime}$ and $\beta$ phase precipitation respectively), while the endothermic effect $\mathrm{V}$ is due to a dissolution reaction ( $\beta^{\prime}$ dissolution). In the other hand, from the microhardness variation as function of temperature, the maximum strengthening corresponds to the precipitates formed at $275^{\circ} \mathrm{C}$ ( $\beta^{\prime \prime}$ phase); due to the large coherency (lattice match) the hardness increase induced by the $\beta^{\prime \prime}$ precipitates is more important than that of the $\beta^{\prime}$ and $\beta$ precipitates.

In view of the foregoing, the response to DSC heating of the as quenched sample agrees reasonably well with the precipitation sequence reported for Al-Mg-Si alloys: supersaturated solid solution (SSSS) $\rightarrow$ atomic cluster and GP zones $\rightarrow \beta^{\prime \prime} \rightarrow \beta^{\prime} \rightarrow$ stable $\beta$.

\subsection{The Natural Aging Effect}

The evolution of the microhardness values as function of natural aging (NA) time is shown in Figure 3. This figure shows that the hardness increases to a maximum during the first $24 \mathrm{~h}$ of the natural aging, then the material shows a plateau with little or no increase in hardness as the time of the NA proceeds.

Figure 4 shows the DSC traces of the as quenched sample and of samples stored at room temperatures for

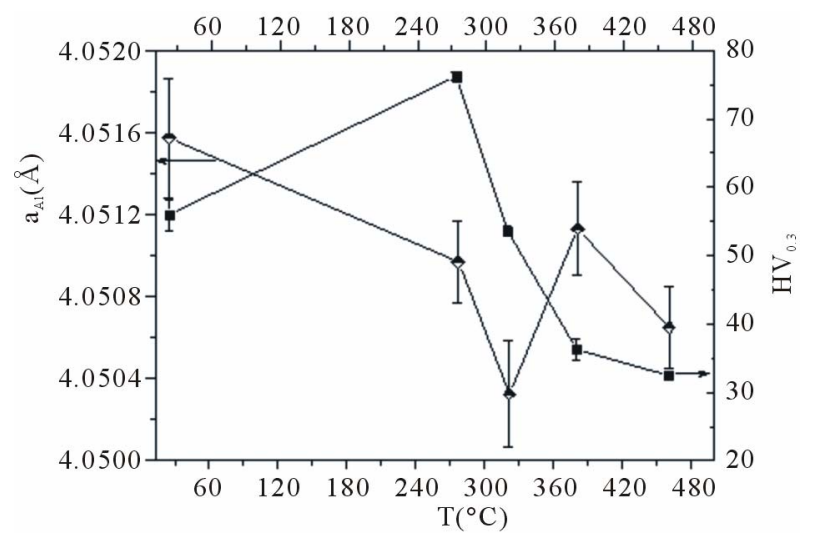

Figure 2. Lattice parameter and microhardness evolution as function of temperature.

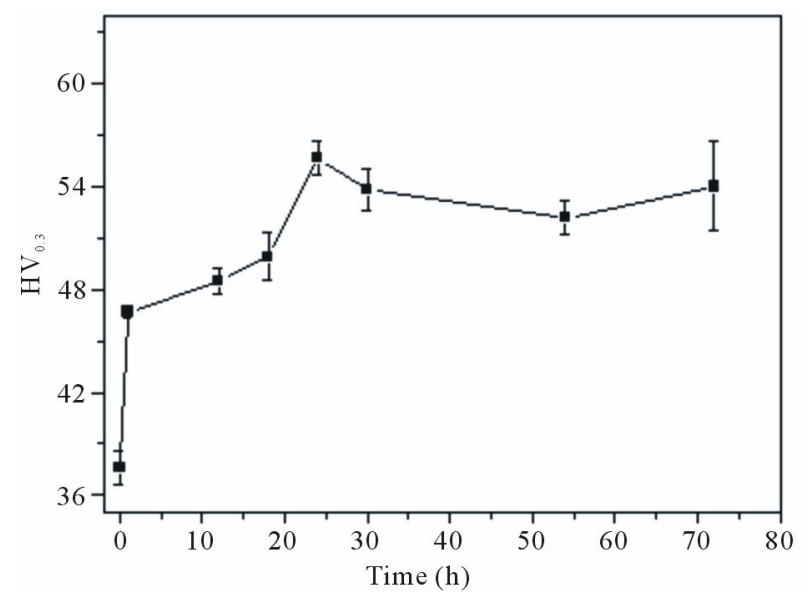

Figure 3. The evolution of the microhardness values as function of natural aging (NA) time.

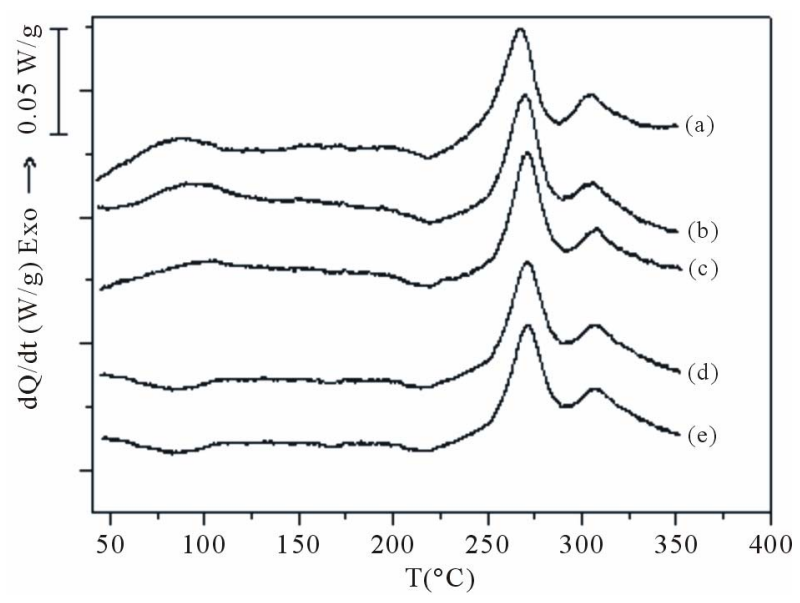

Figure 4. DSC traces obtained at a heating rate of $10^{\circ} \mathrm{C} \cdot \mathrm{min}^{-1}$ of the as quenched sample (a) and of samples stored at room temperatures for times; $2 \mathrm{~h} \mathrm{(b);12} \mathrm{h} \mathrm{(c);} 18 \mathrm{~h}$ (d) and 14 days (e) after quenching.

times corresponding to different points of hardening curve (Figure 3).

After $2 \mathrm{~h}$, clearly, the clusters/GP zones peak area decreases, however the higher temperatures peaks appears to be unchanged. This decreasing of clusters/GP zones peak is confirmed for longer NA times and after $12 \mathrm{~h}$ it appears to be nearly completely suppressed. For longer NA times $(>12 \mathrm{~h})$, one can state the appearance of a small dissolution peak between approximately $50^{\circ} \mathrm{C}$ and $110^{\circ} \mathrm{C}$

When the natural aging is increased, the enthalpic effect corresponding to the clusters/GP zones formation decreases, indicating that those phases are already precipitated during the time spent at room temperature. The small endothermic peak observed for longer NA times can be explained by the dissolution of Mg clusters: in references [12] and [19], it was mentioned that three clustering reactions can take place, and the proposed ini- 
tial clustering sequence is as follows: S.S.S. Al $\rightarrow$ formation of independent clusters of $\mathrm{Mg}$ and $\mathrm{Si}$ atoms $\rightarrow$ dissolution of $\mathrm{Mg}$ clusters $\rightarrow$ formation of $\mathrm{Mg} / \mathrm{Si}$ coclusters. It can be therefore guessed that clusters of $\mathrm{Mg}$ and $\mathrm{Si}$ atoms and GP zones are the responsible for the microhardness increase.

\subsection{The Effect of Natural Aging on the Strengthening during Artificial Aging at $160^{\circ} \mathrm{C}$}

Age hardening curves obtained from the alloy artificially aged at $160^{\circ} \mathrm{C}$ with and with out room temperature storage (for 1 day), are shown in Figure 5.

In the case of samples isothermally annealed at $160^{\circ} \mathrm{C}$ without RT storage (Figure 5(a)), during the initial stages the hardness increases drastically from a value of $(37.1 \pm 1) \mathrm{HV}$ given by the S.S.S. to a maximum of hardness of $(103.3 \pm 2) \mathrm{HV}$ obtained after $8 \mathrm{~h}$ of aging. This is followed by a plateau during which there is little or no increase.

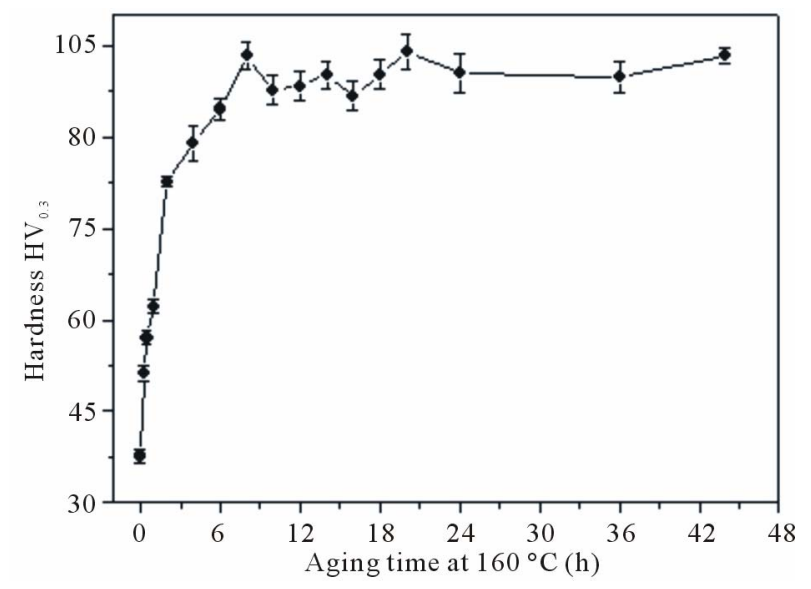

(a)

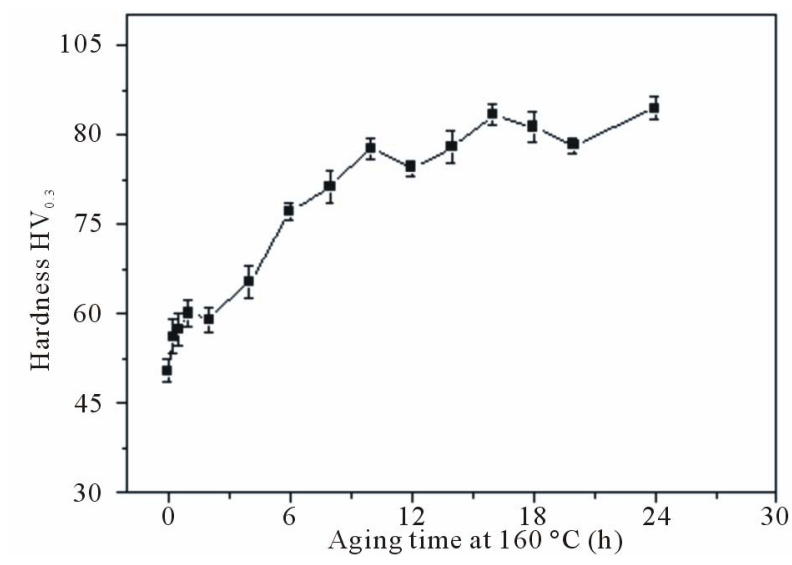

(b)

Figure 5. Hardening curves obtained by artificial aging at $160^{\circ} \mathrm{C}$; right after quenching (a), and after 1 day of $\mathrm{RT}$ storage after quenching (b).
The specimens stored first at RT for one day and then followed by the same annealing treatments at $160^{\circ} \mathrm{C}$ (Figure 5(b)) exhibit almost the same behaviour as those without room temperature storage. However, in contrast with the non-RT aged specimens, the kinetics of microhardness increase for one day stored series are slower; a maximum of $(93.3 \pm 1.8) \mathrm{HV}$ is achieved after $16 \mathrm{~h}$ of aging. For higher aging time, one can observe a plateau with little or no increase in hardness. Thus, the age hardening behaviour was influenced by RT storage in the usual manner that the aging curves of both cases presented almost the same evolution; however, the aging after one day RT storage produced a later and somewhat lower peak hardness when compared with aging without RT storage.

In Figure 6 are presented the lattice parameter variations during aging at $160^{\circ} \mathrm{C}$ of the as quenched sample. The lattice parameter varied rather erratically with aging time, reflecting a complex sequence of structural changes, while the hardness increased monotonically during the artificial aging (Figure 5(a)). Hence, understanding the exact sequence of events in detail may not be immediately possible.

To determine the structural changes during artificial aging that cause the microhardness and lattice parameter variations, homogenized and quenched specimens were aged at $160^{\circ} \mathrm{C}$ to the conditions corresponding to the states $30 \mathrm{~min}, 4 \mathrm{~h}, 8 \mathrm{~h}, 12 \mathrm{~h}, 16 \mathrm{~h}$ and $24 \mathrm{~h}$ were subjected to DSC at a heating rate of $10^{\circ} \mathrm{C} / \mathrm{min}$. Figure 7 shows the obtained DSC curves. It shows that after 30 min of aging at $160^{\circ} \mathrm{C}$, the atomic clusters/GP zones peak has already disappeared completely and the area of the calorimetric peak due to the precipitation of $\beta^{\prime \prime}$ decreased. It is also obvious that increasing aging time leads to a progressive decreasing of the calorimetric peak attributed to $\beta^{\prime \prime}$ formation and its complete disappearance after $16 \mathrm{~h}$ of aging. However, the area and temperature of the $\beta^{\prime}$

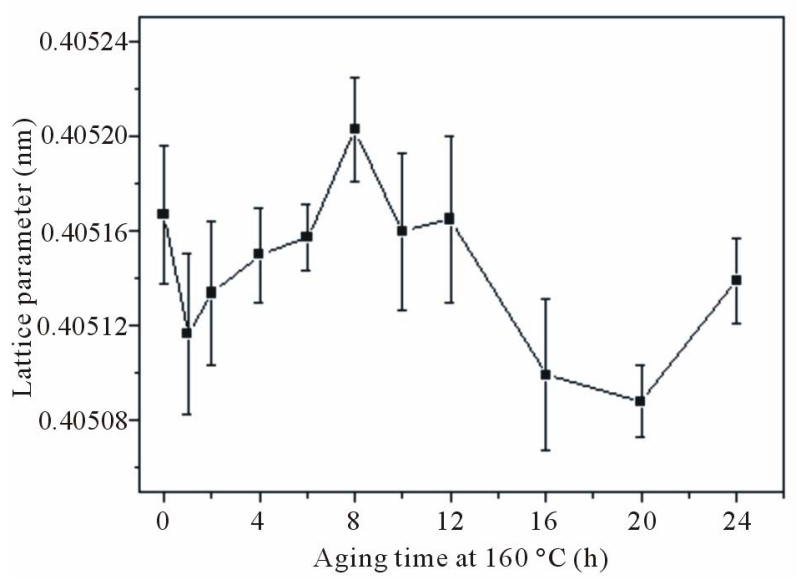

Figure 6. Variations in the $\alpha$-Al lattice parameter as function of time aging at $160^{\circ} \mathrm{C}$ of as quenched samples. 


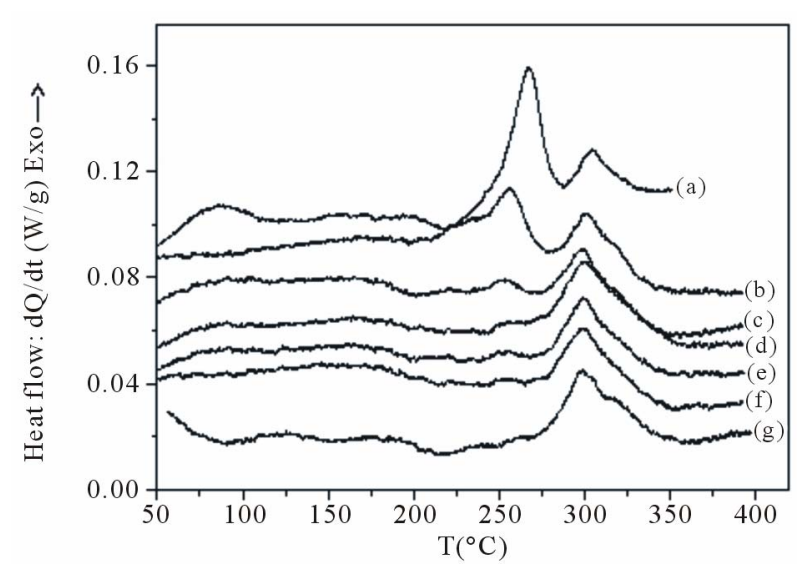

Figure 7. DSC traces obtained at a heating rate of $10^{\circ} \mathrm{C} \cdot \mathrm{min}^{-1}$ of the as quenched sample (a) and aged samples at $160^{\circ} \mathrm{C}$ for; (b) $0.5 \mathrm{~h}$; (c) $4 \mathrm{~h}$; (d) $8 \mathrm{~h}$; (e) $12 \mathrm{~h}$; (f) $16 \mathrm{~h}$ and (g) $24 \mathrm{~h}$; right after quenching.

formation peak seem to be not influenced by the aging treatment. A surprising point, that can be drawn from these DSC results, is the presence of the endothermic peak which was correlated to the atomic clusters/GP zones dissolution (the endothermic effect in the temperature interval $\left[200^{\circ} \mathrm{C}-300^{\circ} \mathrm{C}\right]$ ) indicating that, besides the $\beta^{\prime \prime}$ formation, GP zones and atomic clusters have been also formed during the aging treatment. So, the increasing of the mechanical properties during the aging at $160^{\circ} \mathrm{C}$ is essentially due to the $\beta^{\prime \prime}$ precipitation and then to the atomic clusters/GP zones formation.

For the aged samples with 1 day RT storage before aging, the DSC traces (Figure 8) present a somewhat different behaviour: from the presented traces, it can be seen that the atomic clusters/GP zones formation peak has already disappeared completely, a slight dissolution peak is observed between $105^{\circ} \mathrm{C}$ and $175^{\circ} \mathrm{C}$, which is clearly observed for higher aging times, the dissolution peak of GP zones is also observed and the area of the calorimetric peak due to the precipitation of $\beta^{\prime \prime}$ decreases progressively with the increasing of the aging time. An other important statement, which can be drawn from these DSC results, is that the kinetics of $\beta^{\prime \prime}$ precipitation are faster when specimens were aged without RT storage. The slight endothermic effect observed between $105^{\circ} \mathrm{C}$ and $175^{\circ} \mathrm{C}$ can be explained by the dissolution of the atomic clusters which were formed during the RT storage or the aging treatment.

In this manner, the reduced and retarded strengthening due to the introduction of RT storage between solution heat treatment and artificial aging can be explained by the difficult precipitation of the $\beta^{\prime \prime}$ phase.

This effect of the RT storage on the microstructural development during the artificial aging can be explained at least in a qualitative manner as follows:

In the case of no storage at RT, after homogenization

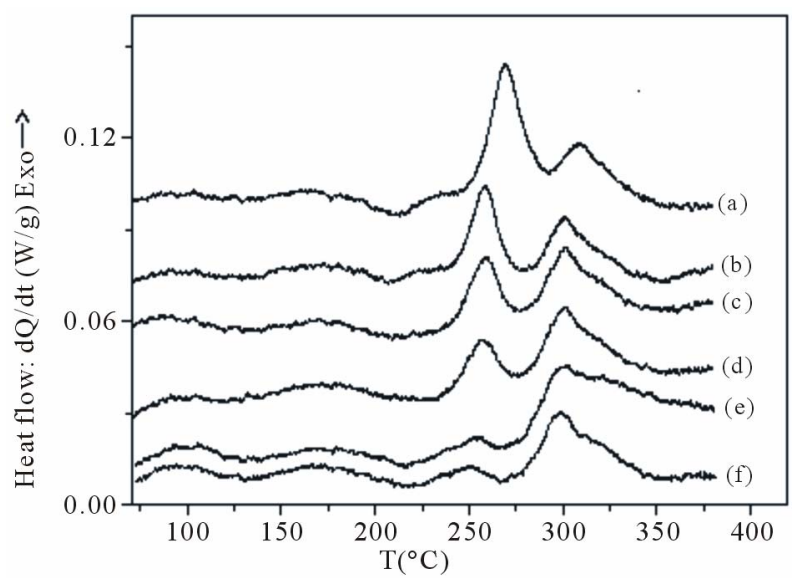

Figure 8. DSC traces obtained at a heating rate of $10^{\circ} \mathrm{C} \cdot \mathrm{min}^{-1}$ of aged samples at $160^{\circ} \mathrm{C}$ for: (a) $0.5 \mathrm{~h}$; (b) $4 \mathrm{~h}$; (c) $8 \mathrm{~h}$; (d) $12 \mathrm{~h}$; (e) $16 \mathrm{~h}$ and (f) $24 \mathrm{~h}$; after 1 day RT storage after quenching.

at $540^{\circ} \mathrm{C}$ a huge amount of non-equilibrium quenched-in vacancies are present in the material. These vacancies enhance the creation of a very large number of coherent phases at the beginning of annealing (GP zones and $\beta^{\prime \prime}$ precipitates). As the aging time increases, there are two continuous processes which can take place: diffusion of $\mathrm{Mg}$ and $\mathrm{Si}$ from the solid solution to the precipitates and replacement of $\mathrm{Al}$ by $\mathrm{Mg}$ and $\mathrm{Si}$ in these precipitates $\left(\beta^{\prime \prime}\right.$ precipitates). The overall result is a fast increase of the microhardness values. However, at the beginning of the annealing treatment at $160^{\circ} \mathrm{C}$ after RT storage, GP zones formed during RT storage are likely to survive. These zones are potential nucleation sites for the $\beta^{\prime \prime}$ phase. The amount of quenched-in vacancies and solute elements has strongly decreased due to the RT aging. The low initial number of vacancies limits the formation of $\beta^{\prime \prime}$ particles. Thus, for the RT stored specimens, during aging, transportation of the $\mathrm{Mg}$ and $\mathrm{Si}$ atoms (from the clusters and the solid solution to $\beta^{\prime \prime}$ nuclei) will be much slower. This reduced diffusion delays the formation of $\beta^{\prime \prime}$ particles. Consequently, the $\beta^{\prime \prime}$ number density is lower than in the case of no storage at RT and the final microstructure developed in these samples is coarse. This explanation is supported by several authors in previous works using different more advanced techniques $[5,8,10,11,15$, 20].

\section{Conclusions}

The precipitation sequence and the effect of RT storage on the microstructural development during artificial aging at $160^{\circ} \mathrm{C}$ of an $\mathrm{Al}-1.45 \% \mathrm{Mg}_{2} \mathrm{Si}-0.4 \% \mathrm{Mg}$ (wt.\%) alloy were studied by a multitude of characterization techniques: DSC, microhardness measurements and XRD analysis. The following conclusions have been drawn:

- The precipitation sequence was identified to be as fol- 
lows: S.S.S. $\rightarrow$ atomic clusters and/or GP zones $\rightarrow \beta^{\prime \prime}$ $\rightarrow \beta \rightarrow \beta$.

- Through DSC analysis, the evolution of the mechanical properties during natural aging has been explained to be due to GP zones and atomic clusters formation.

- During artificial aging at $160^{\circ} \mathrm{C}$, the lattice parameter varied rather erratically with aging time, reflecting a complex sequence of structural changes. Hence, understanding the exact sequence of events in detail may not be immediately possible.

- Under the light of the DSC analysis, the strengthening of the studied alloy during the aging at $160^{\circ} \mathrm{C}$ is essentially due to the $\beta^{\prime \prime}$ precipitation and then to GP zones formation.

Storage at RT was found to have an important effect on the mechanical properties of the studied alloy. Under the light of the DSC results, this effect was explained by a slower precipitation kinetics of the $\beta^{\prime \prime}$ phase; the atomic clusters and GP zones, which formed during storage at $\mathrm{RT}$ and the low concentration of the quenched-in vacancies in the stored samples have a delaying effect upon the nucleation of $\beta^{\prime \prime}$ phase. This effect was attributed to the low initial number of vacancies which reduces the diffusion of $\mathrm{Mg}$ and $\mathrm{Si}$ atoms from the clusters and the solid solution to $\beta^{\prime \prime}$ nuclei. Consequently, the final microstructure developed in these samples is coarse; hence lower mechanical properties are obtained.

\section{REFERENCES}

[1] V. M. Lebedev, V. T. Lebedev, I. N. Ivanova, S. P. Orlov and D. N. Orlova, "Structure of Aluminum Alloys Irradiated with Reactor Neutrons," Physics of the Solid State, Vol. 52, No. 5, 2010, pp. 996-999. doi:10.1134/S1063783410050239

[2] J. V. De Langkruis, M. S. Vossenberg, W. H. Kool and S. Van der Zwaag, "A Study on the $\beta^{\prime}$ and $\beta^{\prime \prime}$ Formation Kinetics in AA6063 Using Differential Scanning Calorimetry," Journal of Materials Engineering and Performance, Vol. 12, No. 4, 2003, pp. 408-413.

[3] O. Myhr, Ø. Grong and K. O. Pedersen, "A Combined Precipitation, Yield Strength and Work Hardening Model for Al-Mg-Si Alloys," Metallurgical and Materials Transactions A, Vol. 41, No. 9, 2010, pp. 2276-2289. doi:10.1007/s11661-010-0258-7

[4] D. G. Eskin, V. Massardier and P. Merle, "A Study of High-Temperature Precipitation in Al-Mg-Si Alloys with an Excess of Silicon," Journal of Materials Science, Vol. 34, No. 4, 1999, pp. 811-820. doi:10.1023/A:1004585216084

[5] K. Fukui, M. Takeda and T. Endo, "The Metastable Phase Responsible for Peak Hardness in the Ageing Temperature Range 403 - 483 K for an Al-Mg-Si Ternary Alloy," Journal of Materials Science, Vol. 40, No. 2, 2005, pp. 3317-3320. doi:10.1007/s10853-005-2710-4

[6] C. D. Mariora, S. J. Andersen, H. W. Zandbergen and R.
Holmestad, "The Influence of Alloy Composition on Precipitates of the Al-Mg-Si System," Metallurgical and Materials Transactions A, Vol. 36, No. 3, 2005, pp. 691702. doi:10.1007/s11661-005-0185-1

[7] R. S. Yassar, M. Cai, D. P. Field, X. Chen and J. Asay, "The Effect of Shock-Loading on the Aging Behavior of an Al-Mg-Si Alloy," Journal of Materials Science, Vol. 41, No. 6, 2006, pp. 1711-1720. doi:10.1007/s10853-006-2933-z

[8] M. Takeda, F. Ohkubo, T. Shirai and K. Fukui, "Stability of Metastable Phases and Microstructures in the Ageing Process of Al-Mg-Si Ternary Alloys," Journal of Materials Science, Vol. 33, No. 9, 1998, pp. 2385-2390. doi:10.1023/A:1004355824857

[9] L. Zhen, W. D. Fei, S. B. Kang and H. W. Kim, "Precipitation Behaviour of Al-Mg-Si Alloys with High Silicon Content," Journal of Materials Science, Vol. 32, No. 7, 1997, pp. 1895-1902. doi:10.1023/A:1018569226499

[10] R. C. Dorward, "Preaging Effects in AI-Mg-Si Alloys Containing 0.6 to 0.9 Pct $\mathrm{Mg}_{2} \mathrm{Si}$," Metallurgical and Materials Transactions B, Vol. 4, No. 2, 1973, pp. 507-512. doi:10.1007/BF02648703

[11] C. D. Mariora, H. Nordmark, S. J. Andersen and R. Holmestad, "Post- $\beta$ " Phases and Their Influence on Microstructure and Hardness in 6xxx Al-Mg-Si Alloys," Journal of Materials Science, Vol. 41, No. 2, 2006, pp. 471478. doi:10.1007/s10853-005-2470-1

[12] C. S. T. Chang and J. Banhart, "Low-Temperature Differential Scanning Calorimetry of an Al-Mg-Si Alloy," Metallurgical and Materials Transactions A, Vol. 42, No. 7, 2011, pp. 1960-1964. doi:10.1007/s11661-010-0596-5

[13] K. D. Woo, J. S. Lee and S. W. Kim, "Calorimetric Investigation of Precipitation Kinetics in AI-Mg-Si-X (Cr, Be) Alloys," Metals and Materials International, Vol. 5, No. 4, 1999, pp. 363-368.

[14] M. Vedani, G. Angella, P. Bassani, D. Ripamonti and A. Tuissi, "DSC Analysis of Strengthening Precipitates in Ultrafine Al-Mg-Si Alloys," Journal of Thermal Analysis and Calorimetry, Vol. 87, No. 1, 2007, pp. 277-284. doi:10.1007/s10973-006-7837-2

[15] Y. Birol, "DSC Analysis of the Precipitation Reaction in AA6005 Alloy," Journal of Thermal Analysis and Calorimetry, Vol. 93, No. 3, 2008, pp. 977-981. doi:10.1007/s10973-007-8686-3

[16] A. Hayoune and D. Hamana, "Structural Evolution during Non-Isothermal Ageing of a Dilute Al-Cu Alloy by Dilatometric Analysis," Journal of Alloys and Compounds, Vol. 474, No. 1-2, 2009, pp. 118-123. doi:10.1016/j.jallcom.2008.06.070

[17] A. Hayoune and D. Hamana, "A Dilatometric and HighTemperature X-Ray Diffraction Study of Cold Deformation Effect on the Interaction between Precipitation, Recovery and Recrystallization Reactions in Al-12 wt.\% Mg Alloy," Materials Science and Engineering: A, Vol. 527, No. 27-28, 2010, pp. 7261-7264. doi:10.1016/j.msea.2010.08.011

[18] G. W. Smith, W. J. Baxter and R. K. Mishra, "Precipitation in 339 and 2124 Aluminum: A Caveat for Calorimetry," Journal of Materials Science, Vol. 35, No. 15, 
2000, pp. 3871-3880. doi:10.1023/A:1004837615783

[19] G. A. Edwards, K. Stiller, G. L. Dunlop and M. J. Couper, "The Precipitation Sequence in Al-Mg-Si Alloys," Acta Materialia, Vol. 46, No. 11, 1998, pp. 3893-3904. doi:10.1016/S1359-6454(98)00059-7
[20] C. D. Marioara, S. J. Andersen, J. Jansen and H. W. Zandbergen, "The Influence of Temperature and Storage Time at RT on Nucleation of the $\beta^{\prime \prime}$ Phase in a 6082 Al-Mg-Si Alloy," Acta Materialia, Vol. 51, No. 3, 2003, pp. 789-796. doi:10.1016/S1359-6454(02)00470-6 